\title{
"SIN RECONOCER SUPERIOR EN LO TEMPORAL"- DISCURSOS DE SOBERANÍA EN LOS REINOS ESPAÑOLES BAJO LOS AUSTRIAS
}

\author{
- "Not recognizing any superior in the profane" - sovereignty discourses in the \\ Spanish kingdoms under the Habsburgs
}

\author{
Matthias Gloël*
}

\begin{abstract}
RESUMEN
Este estudio compara los discursos de soberanía en Castilla, Cataluña y Portugal durante los reinados de los Austrias. Se establece en qué sentido hay que entender "soberanía" en la Edad Moderna y que reside en el príncipe, por lo cual los discursos de soberanía están enfocados en dicha persona del príncipe. Estos discursos sirven para mostrar que el príncipe de un territorio no reconoce a ningún superior en lo temporal. Primero, se analizan los discursos en Castilla que por un lado, rechazan cualquier subordinación al Sacro Imperio y por otro lado pretenden que el rey de Castilla históricamente tiene la soberanía sobre todos los reinos de España. Los discursos en Cataluña y Portugal, en cambio, si bien también contienen algún rechazo al imperio, se dedican principalmente a enfatizar su soberanía frente a Castilla, es decir, rechazan este segundo discurso elaborado por los autores castellanos.
\end{abstract}

Palabras clave: Sacro Imperio, monarquía hispánica, soberanía, Historia Moderna.

\footnotetext{
* Facultad de Ciencias Sociales, Departamento de Sociología y Ciencias Políticas, Universidad Católica de Temuco. Temuco, Chile. Correo electrónico:mgloel@uct.cl

Artículo recibido el 18 de diciembre de 2017. Aceptado el 26 de febrero de 2018.
} 


\begin{abstract}
This study compares sovereignty discourses in Castile, Catalonia and Portugal during the reigns of the Habsburg dynasty. We will clarify in which way sovereignty has to be understood and that it lies in the prince, which is why these discourses focus mainly on this royal person. The aim of the discourses is to show that the prince of a territory does not recognize any other superior temporal power. First, we analyse the Castilian discourses, which, on the one hand, reject any subordination under the Holy Empire and, on the other hand, they do pretend that the Castilian king historically is the sovereign of all the Spanish kingdoms. The discourses in Catalonia and Portugal, by contrast, although they contain some rejections to the empire, focus mainly on emphasizing their sovereignty against Castile, which means that they reject this second discourse elaborated by the Castilian authors.
\end{abstract}

Keywords: Holy Empire, Spanish Monarchy, Sovereignty, Early Modern History,

\title{
Introducción
}

Fue Jean Bodin quien en su obra Les Six Livres de la République (1577) definió la soberanía, particularmente en el capítulo VIII, el cual lleva precisamente el nombre De la Souverainité. Bodin señala que hasta el momento no existe ninguna definición del término soberanía, ni jurídica ni desde la filosofía política, por lo cual él mismo la define así: “La souverainité est la puissance absoluë \& perpetuelle d'une Republique" (Bodin, 1577: 89). De los tres tipos de república que existen según Bodin (estado popular, aristocrático y real), el autor define la monarquía real como el mejor y natural: "Combien qu'il n'est pas besoin d'insister beaucoup, pour monstrer que la Monarchie est la plus seure, veu que la famille, qui est la vraye image de un Republique, ne peut avoire qu'un chef" (Bodin, 1577: 734). Este "chef" al que se refiere Bodin representa, por supuesto, al príncipe, en el cual, por lo tanto, reside la soberanía de un territorio. El único poder por encima de los príncipes para Bodin es el divino, como deja claro en su prefacio: "la conservation des Royaumes \& 
Empires, \& de tous peuples depend apres Dieu, des bons Princes" (Bodin, 1577: prefacio).

Tal como lo afirma la definición de Bodin, el rey en la Baja Edad Media y más todavía en la Edad Moderna es legislador y juez en una sola persona (García Marín, 1998: 21). Pietro Costa ya defendió la viabilidad del concepto soberanía para la Edad Media señalando que no necesariamente se tiene que asociar al estado moderno aunque quede "significativamente débil" (2007: 36). Con dichas funciones el rey impartía justicia, lo cual era considerado como su tarea principal. Costa incluso afirma que "el rey-juez es la expresión y la materialización de una imagen sagrada de la soberanía" (2007: 40).

Ahora bien, un príncipe solo podía ser soberano si no era vasallo de otro príncipe, sea otro rey o sea el emperador. En este sentido se desarrollaron en la España de los Austrias una serie de discursos para justificar esta soberanía. Sin embargo, al ser la monarquía un conjunto compuesto de varios reinos (Elliott, 1992), dichos discursos tienen una mayor diversidad de lo que muchas veces se asume. Se han estudiado mucho más a los textos castellanos que los escritos en los demás reinos españoles (Ballester Rodríguez, 2010), por lo cual una comparación de los argumentos y dimensiones discutidos en los distintos territorios es necesario para poderse percatar de las similitudes y de las diferencias.

La composición de la monarquía hispánica como monarquía compuesta, monarquía policéntrica (Cardim et al., 2012) o monarquía de cortes ha sido trabajada de forma muy exhaustiva desde los años 90, más recientemente por Rivero Rodríguez (2017). El monarca era el principal elemento en común de los distintos territorios, sin que estos se unificaran ni políticamente ni jurídicamente. El rey, por lo tanto, no ostentaba el título de rey de España sino era titular de cada uno de sus territorios por separado (Gloël, 2018). Si bien es cierto que desde fuera se percibía la monarquía como un conjunto hasta cierto 
punto unitario (Cuart Moner, 2004: 123), dentro de la monarquía se observaban y se cuidaban las diferencias, especialmente en los reinos no castellanos.

\section{Los discursos en Castilla}

Acerca de la monarquía

A fines del siglo XVI, en Castilla se empieza a usar el término "monarquía" para describir a los vastos territorios de la rama española de los Austrias, siendo Gregorio López Madera probablemente el primero en hacerlo, ya que la rama austriaca se había quedado con la dignidad imperial tras la abdicación de Carlos V en 1556. Ha sido Irving A.A. Thompson quien destacó la ausencia del término durante casi todo el siglo XVI y el mismo autor define su aparición como un neologismo que "responde a la conciencia contemporánea de la necesidad, y como consecuencia de la invención de un nuevo concepto político" (2005: 34). Sin embargo, este uso no era completamente libre de complicaciones, ya que teóricamente "monarquía" no definía el estatus de un monarca sino representaba un poder universal (Rodríguez Salgado, 1996: 89).

Originalmente, en la Europa cristiana existían dos poderes universales, el imperio y el papado. El papa era dueño de la Monarchia Ecclesiae y el emperador el de la Monarchia Imperii (Bosbach, 1988: 19). Los demás reyes se encontraban subordinados, al papa en lo espiritual y al emperador en lo temporal. Sin embargo, en la realidad política ni el papa ni el emperador eran capaces de imponer su voluntad sobre ellos.

En los tratados castellanos se defiende sobre todo la soberanía de la monarquía como conjunto y, por lo tanto, del monarca también como soberano del todo. Un ejemplo de ello es Gregorio López Madera (1597) cuya obra según Salustiano de Dios de Dios tenía el propósito de "mostrarle que el rey y reino de España eran superiores, al menos en antigüedad, al rey y reino de Francia" (Dios de Dios, 1997: 314). Si bien las comparaciones con Francia ocupan una parte importante de la obra, como veremos más adelante, creemos que abarca 
también la defensa de la soberanía de la monarquía en general, particularmente frente al imperio.

Para aclarar el término "monarquía”, López Madera define brevemente el significado que se le suele dar y lo que significa para él. El autor afirma que existen distintos significados de monarquía y monarca pero que en el fondo se podría concluir que todos se reducen a lo mismo que es el sentido griego de "Principe unico y sola". Para López Madera, sin embargo, esta definición sería solamente válida para Dios y para el papa que efectivamente representa un poder universal en lo espiritual. En cambio, "en lo temporal nunca ha avido tal Principe", por lo cual monarca en este caso significa "el Rey, y cabeça que lo govierna todo, y en esta manera es Monarcha qualquiera que solo govierna y rige algun Reyno, o estado" (López Madera: 1597: 6v). Este planteamiento estaría en concordancia con la fórmula Rex in regno suo imperator est, según la cual todos los príncipes serían monarcas si no son vasallos de otro príncipe. Como señala Antoni Simon i Tarrés, se detecta una clara influencia de Bodin en estos textos que definen España como un señorío sin superior (2005: 106).

Sin embargo, el autor no se queda con esta idea sino afirma que monarquía por excelencia solo sería "el Reyno mas poderoso, y que mas Reynos, y Provincias tuviesse subjetas", tal como ya lo habría definido en la antigüedad el historiador romano Fabio Píctor (López Madera: 1597: 7). Entonces, aunque no se trataba de un título oficial, ya que no era concedido por el papa, lo usa López Madera para expresar la aspiración de la monarquía hispánica de ser la entidad política más poderosa y más importante del presente. Una visión parecida ofrece Juan de Salazar en su Política Española (1619), en la cual afirma que "con razon se llama Monarquia el dominio y superioridad que tiene al presente España sobre tantos Reinos, Provincias tan diversas, i tan amplos i ricos estados i señorios". En concordancia con lo anterior señala a continuación que el término monarca ahora tiene dos significados: el primero es el que le dio Aristóteles que es "unico i soberano Principe, essempto, i sin 
dependencia de otro". El segundo significado, sin embargo, limita bastante al primero ya que ahora (en tiempos de Salazar) se entendería solo al "mayor de los Reyes" como monarca (Salazar, 1619: 1-2).

Esta visión hacia el término de monarca, expresada por López Madera y Salazar contiene tanto una continuidad como una ruptura con el concepto tradicional. Como hemos referido más arriba, el emperador era dueño de la Monarchia Imperii, por lo cual monarquía e imperio eran dos nociones completamente ligadas entre sí y el monarca era el que ostentaba la dignidad imperial y con ella estaba por encima de los demás reyes. Ahí radica la continuidad en el concepto de monarca expresado por los dos autores quienes también lo ven superior a los demás reyes, solo que, y ahí radica la ruptura, no es por una dignidad universal otorgada sino por el poder y los dominios que realmente posee.

Salazar y Mendoza también afirma que es España quien merece el título de monarquía. Señala que ya en la época de los Godos, la cual define como "la niñez de su Soberanía", España merecía dicho título y "muy mas dignamente lo merece hoy, que sin decir mucho es el Rey Católico el mayor Principe que ha visto, ni tenido el mundo desde su creacion" (Salazar y Mendoza, I, 1770: $\mathrm{XXV}$ ). Tras estas afirmaciones hechas ya en el prólogo de su obra retoma el tema de la soberanía más adelante afirmando que España "no reconoce superior en lo temporal, y son sus Reyes Principes libres, Soberanos y Monarcas desde el tiempo que los Godos la empezaron á poseer" (Salazar y Mendoza, I, 1770: 34). López Madera se refiere más expresamente a la dignidad imperial, señalando que si habitualmente se afirma que el emperador es superior a todos los reyes, los defensores de tal teoría no suelen aportar prueba o argumento alguno para convencer a otros. Para el autor, el título imperial no solo no significa más dignidad que el real sino más bien menos ya que tradicionalmente se otorgaba tal título a capitanes famosos por haber ganado algunas batallas, dando algunos ejemplos de la antigua Grecia y Roma. Solo mucho más tarde 
se habría convertido en un título de gobernante porque Cesar y Augusto no querían usar el de rey que en Roma "avian dado por enemigo quando echaron a os Tarquinos" (López Madera, 1597: 7v). Concluye, por lo tanto, al igual que Salazar y Mendoza que los Reyes de España son como mínimo iguales a los emperadores, "señores absolutos sin superior en lo temporal", y que tienen "las mismas prerogativas, y privilegios, que los Emperadores en su Imperio" (López Madera, 1597: 12-12v).

Ahora bien, aunque parece que López Madera establece una diferencia muy clara con el Imperio, esto es solo el caso para la entidad política del Sacro Imperio pero no para el término "imperio" de por sí. Si bien es cierto que lo usa poco, hacia el final de su obra define a la monarquía como el "mayor Imperio que jamas ha avido", ya que es mucho mayor que cualquiera de los que han existido en el pasado (López Madera, 1597: 66). El hecho que se podía usar dicho término en contextos fuera del Sacro Imperio confirma que efectivamente este había dejado de tener aspiraciones universales y se encontraba ahora al mismo nivel que los demás monarcas europeos. Esta interpretación queda apoyada también en el hecho de que después de Carlos V, los emperadores ya no se dejaban coronar por el papa, por lo cual debían entender que su dignidad imperial ya no se fundaba en el Pontífice y se podría interpretar a la vez como una renuncia indirecta de la universalidad.

Salazar de Mendoza también emplea el término imperio en su prólogo y establece incluso una comparación y con ello un vínculo con las "Monarquias Universales, que la Antiguedad ha celebrado por famosas". Según el autor, habrían existido cinco de dichas monarquías, los cuales eran de los asirios, los caldeos, los persas, los griegos y los romanos (Salazar y Mendoza, I, 1770: $\mathrm{XXV)}$. Por una parte, nombrando a cinco monarquías anteriores se desmarca de la teoría del translatio imperii, basada en la Biblia, concretamente en el libro de Daniel, y según la cual la historia de la humanidad transcurre de forma lineal pasando el dominio de un príncipe al terminar siempre a otro. La interpretación 
que se hacía del libro de Daniel a partir de San Jerónimo es que han existido cuatro imperios, Babilonia (Caldeos), Persia, Grecia y Roma y de los cuales el romano continuaría existiendo en el Sacro Imperio. No podía haber un quinto imperio ya que se suponía que con el fin del cuarto llegaría también el fin del mundo.

El autor continúa afirmando que de estas monarquías antiguas, la romana sin duda, fue la mayor para después argumentar que la española sola es mayor que las cinco antiguas juntas, siendo "el Imperio de España mas de veinte veces mayor que lo fue el Romano" (Salazar y Mendoza, I, 1770: XXVI-XXVII). Entonces, aunque el autor no establece una relación directa con el translatio imperii, sí usa el término imperio y asocia indirectamente la monarquía española con los imperios clásicos.

Juan de Salazar, en cambio, crea una conexión mucho más explícita de la monarquía española con la monarquía universal, es decir, el imperio tradicional. Compara la monarquía universal con el movimiento del sol que en un día que amanece en el oriente para al final ponerse en el occidente. Así, de la misma forma "començando la Monarquia universal en el Oriente, de las manos de Assirios, Medos i Persas, Griegos, i Romanos, vino à parar en el Occidente: en las de Españoles" (Salazar, 1619: prólogo). Más adelante, al igual que Salazar de Mendoza, eleva la monarquía española por encima de las anteriores señalando su mayor grandeza y poderío, "siendo el mayor imperio, que desde la creacion del mismo se ha hasta nuestros tiempos conocido" (Salazar, 1619: 2).

Según Pablo Fernández Albaladejo, en el siglo XVI la monarquía universal ya era un concepto anacrónico (1992: 68). Sin embargo, con Carlos V siendo emperador y al mismo tiempo rey de las coronas de Castilla y Aragón, con sus posesiones en América y en el Mediterráneo incluidas, había la posibilidad de que resurgiera la idea de la monarquía universal. Eso era particularmente válido hasta 1530 cuando murió Gattinara, el cual era el consejero más influyente del emperador durante la década de los 1520 y quien era un gran defensor de la idea 
de la monarquía universal (Rivero Rodríguez, 2005: 129-148).

La idea de la monarquía universal, sin embargo, no muere ni con Gattinara ni con Carlos V y la separación de su herencia entre su hijo Felipe y su hermano Fernando. Los párrafos precedentes muestran una fuerte presencia de dicho concepto en los tratadistas castellanos a finales del siglo XVI y la primera parte del siglo XVII. Como señala José Martínez Millán, el proyecto universalista se convirtió en un proyecto familiar de los Habsburgo, liderado por los monarcas españoles, de Felipe II a Felipe IV (2011: 10). Asimismo afirma Bosbach que la aspiración de un liderazgo universalista de los Austrias continuaba existiendo en el siglo XVII, al menos hasta el final de la Guerra de los Treinta Años (2011: 78). También los enemigos de la monarquía hispánica le atribuían estas aspiraciones universalistas, usándolas como justificación de la defensa y guerra justa que les estaban haciendo a los Habsburgo (Bosbach, 2011: 79-80).

Varios autores emplean otra vía más, la histórica, para negar cualquier subordinación de España al imperio, rechazando posibles argumentos en su contra. Como es algo que difícilmente se puede refutar, López Madera no tiene problemas en admitir que España estuvo sujeta al Imperio Romano. Ello, sin embargo, no implicaría ninguna subordinación de España ahora al Sacro Imperio, no porque sea otra entidad política (recordemos que el imperio romano continúa en el Sacro Imperio) sino porque "España salio justissimamente desta, desde el principio de sus Reyes Godos". Por ello, señala el autor que "los Españoles desde que tuvimos Reyes, nunca conocimos, ni reconocimos algun Emperador, sino siendo juntamente Rey nuestro", una clara alusión a Carlos V (López Madera, 1597: 9v-10).

De igual manera afirma Salazar y Mendoza, aunque no niega la subordinación al imperio romano, que los godos no fueron ni súbditos ni vasallos del imperio ya que hubo una donación del emperador hacia los godos que era total y perpetua. Por eso, los reyes comenzarían su titulación con la referencia 
"por la gracias de Dios", ya que "en lo temporal reconocen á solo Dios por superior" (Salazar y Mendoza, I, 1770: 62). También cronistas castellanos apoyan esta argumentación histórica. Julián del Castillo señala que los godos ya en la época de la República Romana rechazaban cualquier subordinación, libertad que siglos más adelante conservarían al convertirse en reyes de España, con lo cual también la propia España se saldría de la subordinación al imperio romano (Castillo, 1624: 15). Esteban de Garibay (1571) confirma la independencia española nuevamente para el siglo XI cuando el emperador le habría solicitado al papa un reconocimiento por parte del rey Fernando I de León, cosa que este no solo rechazó sino además se hizo llamar "Emperador de toda Castilla, Leon y Galicia, siendo el mayor señor, que avia en los reynos de España" (Garibay, II, 1628: 10-11).

Acerca de los reinos españoles

En los textos castellanos se encuentra habitualmente una división entre una Castilla predominante y preeminente y los demás reinos españoles subordinados a ella. López Madera (1597: 22v) y Garibay (1628 I: 419) definen Castilla como "cabeça de España". Garibay explica que Castilla sería el mayor y mejor reino y además el más poblado, por lo cual "los reyes la han reconocido siempre por cabeça, no solo de España mas tambien de todos los demas Reynos y estados que fuera della posseen" (1628 I: 420).

También destacados arbitristas contribuyen a este discurso castellano, como es el caso de Baltasar Álamos de Barrientos (1599) o Pedro Fernández Navarrete (1626). Navarrete define Castilla como "cabeça del imperio", destinada a dominar sobre los demás (1626: 151). Álamos de Barrientos caracteriza Castilla en una primera instancia como "cabeza de esta monarquía", tal como lo habrían sido anteriormente Roma, Constantinopla, Macedonia y Persia (1990: 26). Más adelante señala a Castilla como "cabeza y principio del 
imperio español e incluso llega a hablar del "imperio castellano” realizando así una casi total identificación de Castilla con la monarquía (Álamos de Barrientos, 1990: 105-107). Una justificación de la preeminencia castellana anteriormente referida la proveen los cronistas castellanos. Se construye una continuidad de la monarquía de los reyes godos en los reyes de Castilla a partir de la mítica figura de don Pelayo como sobrino y pariente más cercano del último rey godo Rodrigo. Diego de Saavedra Fajardo en su Corona gótica (1646) argumenta que si bien se suele referir a Rodrigo como último rey godo, esto valdría para el título pero no para la sangre. Aunque sus sucesores se llamaban reyes de Asturias, León y Castilla, el primero de dichos reyes don Pelayo tuvo "la misma sangre real de los godos", con lo cual la sucesión en el trono habría continuado hasta estos días (Saavedra y Fajardo, 2008: 571). Juan de Mariana (1601) también legitima la elección de Pelayo que "venia de la acuña y sangre real de los godos" (1854: 189). De esa forma, López Madera puede sacar la conclusión que a pesar de la invasión de los moros no se interrumpió la sucesión de los reyes godos, “antes se continuo la de los ultimos Reyes, cuyo pariente mas cercano, y principal era el Rey Don Pelayo" (1597: 33). Salazar y Mendoza justifica el derecho de Pelayo con el hecho de que su elección habría sido "conforme á las Leyes de los Godos". Su conclusión es que "fue el Rey D. Pelayo solo el verdadero Señor y dueño de esta Monarquia, por concurrir en él solo para serlo todas las qualidades y circunstancias necesarias” (Salazar y Mendoza, I, 1770: 84).

Esta visión histórica implica la aspiración castellana que sus reyes en realidad podían legítimamente pretender todos los reinos españoles que se habían ido formando después de la invasión de los moros, ya que los demás reyes no poseían la misma legitimidad que los de Castilla. Por ello, señala López Madera que los reyes de Castilla y León siempre exigían "que les avian de reconocer superioridad, y vassallage todos los demas Reynos, que en España se avian alçado" (López Madera, 1597: 72). Julián del Castillo afirma que el rey de Castilla por el derecho señorío debía llamarse rey de España y que a 
los reyes de Castilla "les quedò el derecho señorio de traer a su Corona todos los Reynos y Provincias de España". Por ello, al tratar de la incorporación de Navarra en 1512 señala que dicho reino "se bolvio a juntar justamente a la Corona della" (Castillo, 1624: 193 y 358). Salazar y Mendoza incluso llega a llamar a los otros reyes españoles "intrusos desde el principio" que habrían usurpado el derecho señorío de los reyes castellanos a toda España (Salazar y Mendoza, I, 1770: 160).

Aunque las crónicas castellanas se suelen presentar como historias de España, su objetivo es principalmente la historia de Castilla y de sus reyes, expresando, como se ha visto, un sentimiento de preponderancia castellana entre el conjunto de los reinos españoles (Cuart Moner, 2004: 83). Como señala Xavier Gil Pujol, "las pretensiones de hegemonía española en la política mundial y las de preponderancia castellana en el interior iban a menudo de la mano durante estos años" (2004: 62). El hecho de que en muchos casos son los mismos autores los cuales elaboran los discursos confirma esta afirmación.

\section{Los discursos fuera de Castilla}

Esta visión castellana de una relación asimétrica entre los distintos reinos españoles y la identificación de Castilla con la monarquía de todos provocó contra discursos en los demás reinos de la península, particularmente en Cataluña y Portugal, territorios en los que nos enfocaremos en esta ocasión. Cataluña dominaba la Corona de Aragón durante la Edad Media y Portugal se unió a la monarquía teniendo ya un imperio propio distribuido en los cuatro continentes entonces conocidos, por lo que el rechazo en estos dos territorios fue el mayor.

Como plantea Jon Arrieta Alberdi de modo general, cada integrante de la monarquía tendía a defender sus particularidades (2004: 310). María Pérez Samper incluso afirma que textos como las relaciones geográficas en Cataluña y 
Portugal estaban expresamente ideados como afirmación de lo propio particular y contra Castilla y su pretendida hegemonía (1992: 42). Para las crónicas, aporta Arrieta Alberdi que sobre todo los discursos fundacionales, es decir, el origen del reino, son un fundamento esencial para justificar la existencia como entidad política aparte (2004: 314-315).

\section{Cataluña}

Un asunto importante en Cataluña era el hecho que en dignidad nobiliaria no se trataba de un reino sino que el señor ostentaba solo el título de Conde de Barcelona como máxima autoridad en el principado. Esto le podría otorgar a Cataluña una menor dignidad como territorio frente a otros territorios españoles que sí eran reinos. Andreu Bosch en su obra Summari, Index, o Epitome dels admirables, y nobilissims titols de honor de Cathalunya, Rossello, y Cerdanya (1628) no solo no niega este hecho sino más bien lo reafirma. El autor establece una cadena de defensa de soberanía, la cual se inicia con la de Cataluña dentro de la Corona de Aragón. Señala que en los condados catalanes el rey de Aragón no tiene "titol de Rey, sino de Comta de Barcelona per tota la Provincia de Catalunya, y aixi mateix de Rossello, y Cerdanya per sa Provincia, y ab aqueixos titols esta obligat intitularse, segons nostres propies lleys" (Bosch, 1628: 178).

Después, Bosch defiende la soberanía de toda la Corona de Aragón frente a Castilla, negando así los discursos de preeminencia castellana que circulaban en aquel reino. Destaca el autor que "no poden pretendre Castella, y Leo superioritat a la corona de Arago", ya que "los Reys de avui gosan de línea de Pare Arago, de Mare Castella, y Leo ab dits casaments dels Reys Catholics, y en regles de honor, precedencia com lo marit tinga la ma dreta, y precedencia ala muller, los fills han de continuar lo mateix honor, majorment com conserven en primer lloch lo titol, familia, y linatge del pare, y en molts parts de Espanya 
sols lo nom del pare, sens mescla de la mare, y aixi se pot dir que totes les successions de Espanya quant ala genealogía dels Reys son de la corona de Arago" (Bosch, 1628: 192).

Finalmente, también defiende la soberanía del monarca español frente al imperio con los mismos argumentos que se emplean en Castilla. Señala Bosch que el rey "no regoneix superior, se pot dir de ell tot lo ques diu del Emperador, no es subjecta al Imperi, es Monarcha en son Regne, quant a sos subdits es com Emperador, y Monarcha, en molts Regnes" y "ab sol lo titol de Rey, preceheix a tots los demes Reys de Europa”. En los párrafos siguientes, esta cadena de soberanía se convierte en un círculo, ya que vuelve a Cataluña pasando por la Corona de Aragón. En cuanto al título particular de Rey de Aragón el autor explica que "los demes titols referits al capitol precedent que son aplicats al Rey de Espanya per sas coronas, son propis tambe com a Rey de Arago, per lo qual Regne no regoneix superior, y gosa les demes soberanies referides". Y siguiendo la misma lógica para Cataluña refiere Bosch que "lo ques ha dit dels Reys de España, y particulars de Arago se ha de aplicar, y es tambe propi en lo poder, y soberania te lo Rey en los Comtats de Barcelona, Rossello, y Cerdanya ab lo titol sol de Comta", por lo cual "se pot dir de ell tot lo ques diu del Emperador, no es tributari a ningu, no regoneix superior, es com Emperador en dits Comtats" (Bosch, 1628: 293-294).

Estevan de Corbera también hace referencia al hecho de que no existe título real en Cataluña para señalar que esto no implica que por ello tenga menos dignidad o grandeza. El soberano en Cataluña habría tenido siempre el título de Conde de Barcelona, "pero con magestad y grandeza real" (Corbera, 1678: 94-95). En otra parte de su obra (escrita antes de 1635) critica a las crónicas "generales de las Españas", escritas en Castilla, por apenas mencionar los hechos gloriosos de los catalanes tratándolos "con mas cortedad que si fueramos extranjeros". Y para resumir en un solo término que la soberanía catalana tiene la misma dignidad que cualquier otra en Europa, Corbera habla 
de la "Monarquía de Cataluña" que habría tenido los mismos orígenes gloriosos que los demás reinos de España que se formaron tras la invasión musulmana de 711 (Corbera, 1678: 4).

Con ello, Corbera se pronuncia también en la argumentación histórica para justificar la soberanía del principado. Obras historiográficas como la de Corbera que se publicaban en aquella época en Cataluña se pueden considerar como una respuesta a las crónicas castellanas que parecían atraer casi la totalidad del interés por el pasado de la Península Ibérica (Baró i Queralt; 2004: 912). La antigüedad representa un valor excepcional en la Edad Moderna, lo cual destaca el propio Corbera al principio de su obra: "en ella se reconoce la dignidad, y admiracion parece que sus cosas son como regla, y dechado para acertar en nuestras acciones guiandonos con sus exemplos, y aprovechandonos con su imitacion" (Corbera, 1678: 1).

Andreu Bosch usa este argumento de la antigüedad para convertir la supuesta desventaja del título inferior (conde) en una ventaja para Cataluña en otro argumento más para defender su soberanía. Señala que solamente Cataluña estaría todavía conservando "lo primer titol antich", llamándose condado mientras todas las demás regiones habrían cambiado el título a lo largo del tiempo (Bosch, 1628: 298). Bosch se refiere al hecho que Castilla, Aragón y Portugal también habían sido condados en su día pero que con el tiempo se convirtieron en reinos. Sin embargo, concluye Bosch, ninguna región se puede sentir superior a Cataluña por este motivo, sino sería más bien el principado que merece alabanza por haber conservado este título tan admirable desde sus inicios. Para él, soberanía, majestad y grandeza no se fundan en el título, "qualsevol fos, sino a la soberania potestat, no regoneixent superior, gosant les regalies supremes", por lo cual el conde de Barcelona tendría la misma soberanía que el emperador (Bosch, 1628: 298). La justificación de un título menor (conde - rey) también se asemeja a la castellana (rey - emperador) que niega la subordinación a un título supuestamente más digno. 
La visión castellana de que solo sus reyes serían los sucesores legítimos de los reyes godos y los demás territorios españoles, por lo tanto subordinados a ella no era compartida en Cataluña. Si bien Corbera menciona los inicios de Castilla en Asturias con el ascenso de Pelayo, habla de un "nuevo reino" que dio inicio a la monarquía de Castilla pero sin que se le incluyan las demás partes de España, ya que precisamente no lo describe como una continuidad de los godos sino como algo nuevo (1678: 294).

Los inicios de Cataluña se describen también de una forma más favorable para justificar la propia soberanía. Tradicionalmente se tenía entendido en Cataluña que a finales del siglo VIII, los francos bajo Carlomagno habían liberado a Barcelona de los moros. Solo con el tiempo los reyes francos habrían dejado salir a Cataluña de la subordinación de ellos. Corbera, en cambio, señala que eran los catalanes que eligieron a Carlomagno como su señor y según él así "comenzò entonçes la Monarquia de los antiguos Condes de Barcelona" (1678: 16). Esta visión niega una supuesta subordinación al reino franco y afirma la libertad originaria de los catalanes, ya que según Corbera hubo una elección voluntaria por parte de ellos.

Jesús Villanueva en su importante aportación sobre la historiografía catalana ha señalado que debido a estos orígenes francos no existía en la Cataluña medieval ningún neogoticismo como en Castilla (Villanueva, 2004: 43). Esto cambió durante el siglo XVI y Villanueva concluye que a fines de dicho siglo la mayoría de la nobleza catalana estaba convencida de descender de los godos (Villanueva, 2004: 46). Francisco Diago en su Historia de los victoriosissimos antiguos Condes de Barcelona (1603) señala que un tal Bera fue el primer conde de Barcelona y lo caracteriza como "Godo caballero valiente" (Diago, 1603: 52v).

Francesc Martí i Viladamor no busca orígenes godos en términos de descendencia sino establece una vinculación con las leyes de los godos. Explica que como hubo una elección en caso de Carlomagno (aquí concuerda 
con Corbera) no hubo transferencia de dominio más allá de su persona, por lo cual "en fuerça de los leyes Goticas, y Decretos Conciliares" pudieron dejar de reconocer a los descendientes de dicho rey franco "y elegir lícitamente otro nuevo Rey y Señor” (Martí i Viladamor, 1641: 55). Según este autor, Cataluña siempre habría tenido su "libertad natural", la cual nunca habría perdido en ningún momento (Martí i Viladamor, 1641: 48). La obra de Martí i Viladamor es en cierto modo un caso particular, ya que se publicó poco después de estallar la revuelta catalana de 1640 y el autor elabora con especial énfasis una teoría de una soberanía de origen popular y reino electivo que haría posible dejar de obedecer a Felipe IV y elegir a otro señor como conde de Barcelona.

Pero también de forma general se puede afirmar que el objetivo de los cronistas catalanes era aumentar el rol que tuvieron los propios catalanes en la recuperación de su territorio de los moros. Al mismo tiempo se le bajaba la importancia de la participación franca en dicha empresa. Algunos autores como García de Queralbs la eliminaron casi por completo. En su Historia de Sant Oleguer señala que al estar ocupada España por los moros el Conde Guifre Pelos le pidió ayuda al rey de Francia (es de asumir que se refiere el rey de los francos), el cual teniendo muchas ocupaciones propias habría renunciado a Cataluña y con ello a cualquier derecho sobre ella. Su conclusión es que los catalanes nunca habrían sido conquistados, "antes bien ellos mismos se han conquistado y librado". Después habrían entregado voluntariamente el poder a sus antiguos condes que luego serían reyes de España (Garcia de Queralbs, 1617: 48v-49).

\section{Portugal}

Como ya hemos visto, la soberanía se suele justificar a través de contextos temáticos sobre los cuales desde otro lado se podría poner en duda, como es un título nobiliario inferior o una posible subordinación a otro territorio 
en el pasado. A diferencia de Cataluña, en Portugal no había un problema con el título del soberano, ya que al igual que Castilla y otros territorios peninsulares tenía la dignidad de reino. Sin embargo, el origen de Portugal sí se encontraba en un condado que además surgió dentro del reino de León.

Históricamente, el noble Enrique de Borgoña sirvió al rey de León Alfonso VI en la conquista de Galicia y como premio dicho rey lo casó con su hija Teresa dándole además el Condado de Portucale, con lo cual se convirtió en vasallo del rey en 1096. Su hijo Alfonso Enríquez se convirtió en rey en 1139 y el condado pasó a ser el reino de Portugal. Por lo tanto, los discursos de soberanía en Portugal se centraban principalmente en la historia, ya que para rechazar una posible subordinación en el propio presente era necesario negar que dicha subordinación hubiera existido alguna vez en el pasado.

Al haber cambiado el título posteriormente, los cronistas portugueses no podían convertir el origen condal de su territorio en una ventaja como lo hicieron los catalanes. La solución que encuentran algunos de los historiadores portugueses es negar que Portugal en algún momento haya sido condado. António Brandão, autor de la tercera parte de la Monarquia Lusitana, lo afirma de la siguiente manera: "E em confirmação da soberania de Portugal, não deixarei de allegar outro fundamento, o qual he que o Reyno de Portugal se não abateo a titulo de Condado, como comúnmente se diz". A continuación, Brandão explica que en el caso del conde se trataba de un título personal de Enrique, por lo cual se puede hablar del Conde Don Enrique pero nunca del Conde de Portugal (1632: 24v). Lo mismo afirma Fernando Oliveira en su opúsculo Livro da Antiguidade, Nobreza, Liberdade e Imunidade do Reino de Portugal, escrito poco antes de 1580 e inédito hasta el año 2000: "De nenhuma maneira destas se lê que Portugal fosse condado de Leão, nem de Castela. Do primeiro modo, não foi seu condado, porque antes que Leão e Castela tivessem ser, Portugal era reino, ou república livre" (Oliveira, 2000b: 508).

La última parte del fragmento de Oliveira ya forma parte de otro 
discurso que complementa al anterior, de la antigüedad del reino portugués. Varios cronistas portugueses buscan el inicio de Portugal como reino no en la historia del conde Enrique y su hijo Alfonso Henríquez sino en dos motivos principalmente. Primero, la dignidad de reino llegaría muy tarde, solo en el siglo XII y segundo, si Brandão y Oliveira argumentan que Portugal nunca fue condado, entonces debe haber sido reino ya de antes. Por ello, se crea otro origen del reino en el pasado mítico del poblamiento posdiluviano por parte de Tubal, figura bíblica y nieto de Noé, un mito que contaba con distintas variantes en las diversas partes de la península (Ballester, 2013; Gloël, 2017). Así lo señala António de Sousa de Macedo: "Si España es el mas antiguo Reyno del mundo, Portugal es el mas antiguo de los de España, porque Tubal, que fue el primero que la poblô, como está assentado por por certissimo entre todos los hombres doctos, la primera tierra en que hizo poblacion, y asiento fue en la villa de Setubal en Portugal" (Sousa de Macedo, 1631: 24v). Oliveira afirma que hubo muchos reyes en Portugal antes de los godos y moros y señala que el hecho que en algún momento no hubo sucesión no quiere decir que Portugal dejara de ser reino y tampoco dejó de llamarse como tal (2000b: 509). Brandão explica que a pesar de que se le tiene a Alfonso Enríquez comúnmente como el primer rey de Portugal, esto no sería así, al "não ser esta a primeira vez que Portugal aparece no mundo com titulo de Reinado. Antiquissimo he este nome, \& a dignidade Real nesta provincia" (1632: 129v).

Un tercer discurso en este contexto se construyó acerca de la pregunta si el conde Enrique era vasallo del rey de León, hipótesis rechazada por muchos cronistas portugueses. Brandão critica a los autores contemporáneos que estarían hablando sin fundamento de una sujeción del conde al rey leonés, cuando en realidad "não houve lugar, nem tempo para o Conde Dom Henrique exercitar acto algum de vassalagem" (1632: 19). Oliveira en su História de Portugal confirma que el conde Enrique ya era "supremo no reino de Portugal", ya que los portugueses eran "povo libre, que não devia cousa alguma aos reis 
de Leão" (2000a: 415).

Sousa de Macedo incorpora este punto en una serie de declaraciones de soberanía que realiza en su obra. Señala para empezar que "es Portugal Monarchia soberana independiente, y sin reconocer superior alguno". Continúa afirmando que "primeramente no reconoce al Imperio" (Sousa de Macedo, 1631: 35-35v). No nos da una definición del término monarquía como se suele ver en los autores castellanos pero sí hace referencia a López Madera y Salazar de Mendoza cuando se refiere al gobierno monárquico, por lo cual es de suponer que maneja un concepto parecido que no reconoce superior en lo temporal. A continuación, Sousa de Macedo declara Portugal también soberano dentro de la monarquía, particularmente frente a Castilla: "Ni tampoco reconoce por superior al Reyno de Leon, y Castilla, como algunos dixeron". En este contexto señala que la entrega del territorio a Enrique por parte del rey leonés se realizó "sin obligacion, ni reconocimiento alguno" (Sousa de Macedo, 1631: 35v.).

Sousa de Macedo además rechaza, al igual como lo hemos visto en autores catalanes, el discurso desarrollado en Castilla, según el cual los reyes de Castilla como sucesores de los reyes godos serían los únicos reyes legítimos de la península. La negación consiste en dos argumentos: primero, al no haber sucesión por herencia en tiempo de los godos, aunque hubiese un descendiente de dichos reyes este no tendría ningún derecho al trono por su ascendencia. Así, en todas partes de España se podía elegir al rey que se quisiera. Esto último por el segundo argumento que señala el autor, que por la conquista de los moros sí habría terminado el reino de los godos, por lo cual no hubo sucesión ni hereditaria ni por elección (Sousa de Macedo, 1631: 36v-37).

Si bien Sousa de Macedo y Brandão escriben unas cinco décadas después de Oliveira, se observa que hay una gran continuidad entre sus argumentos. Ya advirtió Pedro Cardim que no es oportuno concebir la década de 1630 como el recorrido hacia una ruptura inevitable que habría sucedido en 1640 (2004: 369). En este sentido, los discursos portugueses hay que entenderlos dentro del 
contexto de la monarquía hispánica y no como precursores de lo que ocurriría en 1640 .

\section{Conclusiones}

Hemos visto que los discursos de soberanía se desarrollan de manera diferente en los distintos reinos españoles. Hay que dejar claro que los argumentos expuestos no pretenden representar a la totalidad de autores que escribían en los diversos reinos durante la época de los Austrias. Sí creemos que representan corrientes muy importantes que tenían mucha influencia que es lo que justifica el haber realizado un estudio comparativo entre ellos.

Entre los autores castellanos hay dos discursos que predominan fundamentalmente. Primero, se niega una subordinación al imperio de los monarcas españoles rechazando así formalmente el poder universal del emperador en lo temporal. En este contexto surge a fines del siglo XVI el término de monarquía en vinculación con España. Este término estaba vinculado estrechamente con el poder universal anteriormente referido y se pretende en el nuevo contexto expresar una superioridad de los reyes españoles por encima de los demás reyes cristianos, desarrollando así una variante hispana de la monarquía universal. Este discurso viene acompañado por otro más de corte histórico. Los teóricos castellanos justifican la independencia de España del imperio por la salida que tuvo del imperio romano con los godos. Al liberarse España de esta forma del imperio romano, el Sacro Imperio, entendido como su continuación, no podía en el presente reclamar subordinación de un territorio que ya hace mucho tiempo que quedó libre.

El segundo discurso principal presente en Castilla es acerca de la soberanía de los reinos españoles dentro de la monarquía, la cual representa el conjunto. Según los autores castellanos, solo Castilla es cabeza de la monarquía y por tanto soberana. Los demás reinos de la península, en cambio, estarían 
subordinados a Castilla. La justificación es histórica: solo los reyes castellanos representarían la continuidad legítima del reino de los godos, por lo cual siempre habrían tenido la realeza en toda España, mientras que los reyes que se levantaron en otras partes no habrían sido legítimos.

Los discursos de los demás reinos se pueden entender principalmente como una respuesta a esta pretensión castellana, ya que apenas defienden la soberanía de la monarquía frente al imperio sino la de su propio reino dentro de la misma. Dichos discursos se enfocan en los posibles puntos débiles de cada uno de los territorios, por donde se podría justificar una subordinación. En Cataluña la debilidad principal se halla en el hecho de no tener título de reino sino solo de condado. Los autores catalanes niegan que este título menor implique algún tipo de subordinación, señalando que los condes de Barcelona gobernarían con la misma dignidad como si fuesen reyes. También existe un discurso histórico complementario que trata de convertir esta posible desventaja en una ventaja para Cataluña. Se argumenta que el título del condado barcelonés sería el más antiguo en toda España, ya que los demás territorios habrían cambiado su título a reino más adelante. Esta antigüedad, criterio muy importante en la época, le daría una preeminencia a Cataluña sobre los demás territorios de la península.

Portugal, en cambio, no tiene el problema de la falta del título real en los siglos XVI y XVII sino que históricamente salió como condado del reino de León, siendo el conde Enrique probablemente vasallo del rey leonés. Para afirmar la soberanía de Portugal, los autores de este reino rechazan ambas partes de este origen histórico. Se niega que Portugal en algún momento fuese condado alegando que el titulo era personal de Enrique y no del territorio. Se afirma, además, que Portugal habría sido reino desde la llegada de la figura bíblica de Tubal después del diluvio sin dejar de serlo nunca a pesar de que hubo épocas en que no existían reyes en Portugal. Con este argumento se exige además una preeminencia portuguesa por ser el reino más antiguo de España. Complementario a esto, se señala que 
la escisión de Portugal del reino leonés habría sido de forma libre sin quedar en subordinación alguna con el rey de León.

A parte de las diferencias también hay cosas importantes en común en los distintos discursos de soberanía. Los argumentos y los valores en que se basan estos son muy similares, como también es el objetivo principal de todos ellos: negar que haya entidad o señor superior en lo temporal. En todos los territorios se emplean argumentos históricos para justificar esta posición. También las definiciones de rey y monarca varían apenas. Incluso algún autor en Cataluña y también en Portugal llega a hablar de la monarquía de Cataluña o monarquía de Portugal, lo cual demuestra que todos se mueven dentro de un mismo contexto de mentalidades, de lo que es valioso y digno, aunque las interpretaciones que se hacen de ellas pueden variar según los intereses particulares de los autores.

\section{Referencias}

Álamos de Barrientos, Baltasar (1990). Discurso político al rey Felipe III al comienzo de su reinado. Barcelona, España: Anthropos.

Arrieta Alberdi, Jon (2004). Las formas de vinculación a la monarquía y de relación entre sus reinos y coronas en la España de los Austrias. En Antonio Álvarez-Ossorio Alvariño y Bernardo José García García (eds.), La monarquía de las naciones. Patria, nación y naturaleza en la monarquía de España (pp. 303-326). Madrid, España: Fundación Carlos de Amberes.

Ballester Rodríguez, Mateo (2010). La identidad española en la Edad Moderna (1556- 1665): discursos, símbolos y mitos. Madrid, España: Tecnos.

Ballester Rodríguez, Mateo (2013). "La estirpe de Tubal: relato bíblico e identidad nacional en España”. Historia y Política, 29, 219-246.

Baró i Queralt, Xavier (2004). La legitimación de los privilegios de Cataluña en la Cataluña Illustrada de Esteve de Corbera. En Francisco José Aranda Pérez (ed.), La declinación de la monarquía hispánica en el siglo XVII (pp. 905-916). Cuenca, España: Ediciones de la Universidad Castilla-La Mancha. 
Bodin, Jean (1577). Les Six Livres de la République. Paris, Francia: Jaques du Puys.

Bosbach, Franz (1988). Monarchia Universalis, Ein politischer Leitbegriff der Frühen Neuzeit. Göttingen, Alemania: Vandenhoek \& Ruprecht.

Bosbach, Franz (2011). Die Habsburger und die Universalmonarchie im Dreißigjährigen Krieg. En José Martínez Millán y Rubén González Cuerva (eds.), La dinastía de los Austrias: las relaciones entre la monarquía católica y el imperio (pp. 71-82). Madrid, España: Polifemo.

Bosch, Andreu (1628). Summari, Index, o Epitome dels admirables, y nobilissims titols de honor de Cathalunya, Rossello, y Cerdanya. Perpiñán, Francia: Pere Lacavalleria.

Brandão, António (1632). Monarchia Lusitana, terceira parte. Lisboa, Portugal: Pedro Craesbeck.

Cardim, Pedro (2004). Los portugueses frente a la Monarquía Hispánica. En A. Álvarez-Ossorio Alvariño y B. García García (eds.), La monarquía de las naciones. Patria, nación y naturaleza en la monarquía de España (pp. 355-383). Madrid, España: Fundación Carlos de Amberes (2004): 355-383.

Cardim, Pedro et al. (eds.). (2012). Polycentric monarchies. How did Early Modern Spain and Portugal achieve and maintain a global hegemony? Eastbourne, Inglaterra: Sussex Academic Press.

Castillo, Julián del (1624). Historia de los reyes godos que vinieron de la Scythia de Europa contra el Imperio Romano, y a España. Madrid, España: Luis Sánchez.

Corbera, Estevan de (1678). Cataluña Illustrada. Nápoles, Italia: Antonino Graminani.

Costa, Pietro (2007). "La soberanía en la cultura político-jurídica medieval: imágenes y teorías”. Res Pública, 17, 33-58.

Cuart Moner, Baltasar (2004). La larga marcha hacia las historias de España en el siglo XVI. En Ricardo García Cárcel (ed.), La construcción de las Historias de España (pp. 45-126). Madrid, España: Marcial Pons.

Diago, Francisco (1603). Historia de los victoriosissimos antiguos Condes de 
Barcelona. Barcelona, España: Sebastian Cormellas.

Dios de Dios, Salustiano de (1997). La doctrina sobre el poder del príncipe en Gregorio López Madera. Anuario de historia del derecho español, 67, 309-330.

Elliott, John H. (1992). A Europe of composite monarchies. Past and Present, $137,48-71$.

Fernández Albaladejo, Pablo (1992). Fragmentos de monarquía, Trabajos de historia política. Madrid, España: Alianza Editorial.

Fernández Navarrete, Pedro (1626). Conservación de monarquías. Madrid, España: Imprenta Real.

Garcia de Queralbs, Antoni (1617). Historia de Sant Oleguer, arçobispo de Tarragona, y obispo de Barcelona. Barcelona, España: Sebastian Matevad.

García Marín, José María (1998). "La doctrina de la soberanía del monarca (1250-1700)". Fundamentos: Cuadernos monográficos de teoría del estado, derecho público e historia constitucional, 1, 21-86.

Garibay, Esteban de (1628). Los quarenta libros del compendio historial de las chronicas y universal historia de todos los Reynos de España. 4 tomos. Barcelona, España: Sebastian de Cormellas.

Gil Pujol, Francisco Xavier. (2004). Un rey, una fe, muchas naciones. Patria y nación en la España de los siglos XVI y XVII. En Antonio ÁlvarezOssorio Alvariño y Bernando García García (eds.), La monarquía de las naciones. Patria, nación y naturaleza en la monarquía de España (pp. 39-76). Madrid, España: Fundación Carlos de Amberes.

Gloël, Matthias (2017). "The Tubal figure in early modern Iberian historiography, 16th and 17th century". Imago Temporis, 11, 27-51.

Gloël, Matthias (2018). "Los conceptos de España durante los reinados de los Austrias". Revista de Humanidades, 38, en prensa.

López Madera, Gregorio (1597). Excelencias de la Monarchia y Reyno de España. Valladolid, España: Diego Fernández de Córdoba.

Mariana, Juan de (1854). Obras del Padre Juan de Mariana. Tomo primero. 
Madrid, España: M. Rivadeneyra, 1854.

Martí i Viladamor, Frances (1641). Noticia Universal de Cataluña. Barcelona, España: Consejo de Ciento de la Ciudad de Barcelona.

Martínez Millán, José (2011). La Casa de Austria: una justificación políticoreligiosa (siglos XVI-XVIII). En José Martínez Millán y Rubén González Cuerva (eds.), La dinastía de los Austrias: las relaciones entre la monarquía católica y el imperio (pp. 9-58). Madrid, España: Polifemo.

Oliveira, Fernando (2000a). História de Portugal. En J. Franco (ed.), O mito de Portugal. A primeira História de Portugal e a sua função política (pp.349-494). Lisboa, Portugal: Roma Editora.

Oliveira, Fernando (2000b). Livro da Antiguidade, Nobreza, Liberdade e Imunidade do Reino de Portugal. En J. Franco (ed.), O mito de Portugal. A primeira História de Portugal e a sua função política (pp. 495-522). Lisboa, Portugal: Roma Editora.

Pérez Samper, María Ángeles (1992). Catalunya i Portugal. El 1640. Dos pobles en una cruïlla. Barcelona, España: Curial.

Rivero Rodríguez, Manuel (2005). Gattinara, Carlos Vy el sueño del imperio. Madrid, España: Silex Ediciones.

Rivero Rodríguez, Manuel (2017). La monarquía de los Austrias. Historia del imperio español. Madrid, España: Alianza Editorial.

Rodríguez Salgado, María José (1996). Patriotismo y política exterior en la España de Carlos V y Felipe II. En F. Ruiz Martín (ed.), La proyección europea de la monarquía hispánica (pp. 49-105). Madrid, España:

Editorial Complutense.

Saavedra y Fajardo, Diego de (2008). Corona gótica. Murcia, España: Tres Fronteras.

Salazar, Juan de (1619). Política Española. Logroño, España: Diego Mares.

Salazar y Mendoza, Pedro de (1770). Monarquía de España, 2 tomos, Madrid, España: Joachin Ibarra.

Simon i Tarrés, Antoni (2005). Construccions polítiques i identitats nacionals. 
Catalunya i els origens de l'Estat modern espanyol. Barcelona, España: Abadia de Montserrat.

Sousa de Macedo, António de (1631). Flores de España, excelencias de Portugal. Lisboa, Portugal: Jorge Rodriguez.

Thompson, I. (2005). La Monarquía de España: la invención de un concepto.

En F. Guillamón Álvarez et al. (eds.), Entre Clío y Casandra. Poder y sociedad en la monarquía hispánica durante la Edad Moderna (pp. 33-56). Murcia, España: Universidad de Murcia.

Villanueva, Jesús (2004). Política y discurso histórico en la España del siglo XVII. Las polémicas sobre los orígenes medievales de Cataluña. Alicante, España: Universidad de Alicante. 